\title{
Assessment of Operational Reliability Indicators of Mine Hydraulic Excavators
}

\author{
Vladimir V. Moskvichev ${ }^{\text {a* }}$ and Maksim A. Kovalev ${ }^{\mathbf{b}}$ \\ ${ }^{a}$ Krasnoyarsk Branch Federal Research Center \\ Information and Computing Technologies \\ Krasnoyarsk, Russian Federation \\ ${ }^{b} L L C$ "MC "Sibanthracite" \\ Novosibirsk, Russian Federation
}

Received 07.07.2020, received in revised form 09.08.2020, accepted 28.08.2020

Abstract. The results of the reliability indicators study of mine hydraulic excavators in the coal mine «Kolyvansky» of JSC «Siberian Anthracite» are presented. The analysis of the reliability indicators changes of the main equipment assemblies and excavators in general is performed. Quantitative values of the random variables have been determined, and the effectiveness of the existing system for collecting and analyzing information about the excavators reliability has been assessed. The rating of reliable hydraulic excavators in the coal mine «Kolyvansky» has been compiled.

Keywords: mining equipment, hydraulic excavators, excavator reliability, mean time to fail, average recovery time, excavator reliability rating.

Citation: Moskvichev V.V., Kovalev M.A. Assessment of operational reliability indicators of mine hydraulic excavators, J. Sib. Fed. Univ. Eng. \& Technol., 2020, 13(6), 745-756. DOI: 10.17516/1999-494X-0263

(C) Siberian Federal University. All rights reserved

This work is licensed under a Creative Commons Attribution-Non Commercial 4.0 International License (CC BY-NC 4.0).

* Corresponding author E-mail address: kovalevmalk@gmail.com 


\title{
Оценка показателей эксплуатационной надежности карьерных гидравлических экскаваторов
}

\author{
В.В. Москвичев ${ }^{\text {a }}$ М.А. Ковалев ${ }^{0}$ \\ ${ }^{a}$ Красноярский филиал \\ Федерального исследовательского изентра \\ информационных и вычислительных технологий \\ Российская Федеращия, Красноярск \\ ${ }^{\sigma} \mathrm{OOO} « \mathrm{УК}$ «Сибантрацитм» \\ Российская Федераџия, Новосибирск
}

\begin{abstract}
Аннотация. Приведены результаты исследования показателей надежности карьерных гидравлических экскаваторов в условиях угольного разреза «Колыванский» $\mathrm{AO}$ «Сибирский Антрацит». Выполнен анализ изменения показателей надежности основных групп оборудования и в целом экскаваторов. Определены количественные значения исследуемых случайных величин, оценена эффективность существующей системы сбора и анализа информации о надежности экскаваторов. Составлен рейтинг надежности среди гидравлических экскаваторов, эксплуатируемых в условиях угольного разреза «Колыванский».
\end{abstract}

Ключевые слова: карьерная техника, гидравлические экскаваторы, надежность экскаваторов, наработка на отказ, среднее время восстановления, рейтинг надежности экскаваторов.

Цитирование: Москвичев, В.В. Оценка показателей эксплуатационной надежности карьерных гидравлических экскаваторов / В.В. Москвичев, М.А. Ковалев // Журн. Сиб. федер. ун-та. Техника и технологии, 2020. 13(6). С. $745-756$. DOI: $10.17516 / 1999-494 X-0263$

\section{Введение}

Горнодобывающая промышленность является одной из основных производственных отраслей России. В 2019 г. объем добычи бурого и каменного угля составил 439,2 млн т, из которых 334,2 млн т (или 76 \%) открытым способом; объем вскрышных работ равен 2248 млн м³ Несмотря на то что в 2019 г. по сравнению с предыдущими годами отмечено значительное снижение цен на уголь на мировом рынке (на 10-40 \% в разные периоды в течение года) [1], приведенные данные свидетельствуют о стабильном развитии горнодобывающей промышленности.

Непрерывное увеличение объемов открытого способа добычи угля сопровождается необходимостью наращивания парка карьерной техники и поддержания ее в работоспособном состоянии. По информации Федеральной службы государственной статистики, степень износа основных фондов предприятий по добыче полезных ископаемых на начало 2019 г. составила по группам: «машины и оборудование» - 64,6 \%, «транспортные средства» - 60,4 \% [2].

Представленные данные свидетельствуют о повышенном износе парка карьерной техники и его моральном старении. Часть эксплуатируемого парка карьерной техники в РФ создавалась либо в советский период, либо до кризиса 2008-2014 гг. и на текущий момент имеет сверхнормативные сроки службы. В данной ситуации важен анализ эксплуатационных показателей надежности экскаваторов, по результатам которого могут быть выработаны стратегии управ-

$$
-746-
$$


Таблица 1. Основные технические параметры КГЭ

Table 1. Main technical parameters of pit hydraulic excavators

\begin{tabular}{|l|c|c|c|}
\hline \multicolumn{1}{|c|}{ Параметры } & Bucyrus RH120E & Liebherr ER9250 & $\begin{array}{c}\text { Liebherr } \\
984 C / 9100\end{array}$ \\
\hline Исходный объем ковша при 1,8 т/м & 15 & 15 & $7 / 7$ \\
\hline Максимальная высота среза, м & 14,4 & 12,8 & $14,75 / 12,7$ \\
\hline Максимальный вылет при копании, м & 13,5 & 13 & $14,65 / 13$ \\
\hline Максимальная высота разгрузки, м & 10,7 & 11 & $9,8 / 8,65$ \\
\hline Эксплуатационная масса, тн & 287 & 253,5 & $119,8 / 109,6$ \\
\hline Давление на грунт, кПа & 215 & 207,9 & $175,3 / 139$ \\
\hline Скорость перемещения, км/ч & 2,7 & 2,7 & $2,9 / 3,5$ \\
\hline Максимальное тяговое усилие, кН & 1680 & 1210 & $560 / 560$ \\
\hline Топливный бак, л & 5360 & 5440 & $1585 / 1478$ \\
\hline Средняя наработка на 01.01.20, м/ч & 47448 & 47302 & 27456 \\
\hline Количество эксплуатируемых экскаваторов, ед. & 2 & 3 & 3 \\
\hline
\end{tabular}

ления парком экскаваторов в целях снижения затрат на их содержание и достижения запланированных объемов выполнения производственной программы.

Анализ эксплуатационных показателей надежности выполнен для карьерных гидравлических экскаваторов (КГЭ), эксплуатируемых АО «Сибирский Антрацит» на Колыванском месторождении Горловского угольного бассейна в Искитимском районе Новосибирской области. Предприятие добывает высококачественный антрацитный уголь категории Ultra High Grade (UHG), запасы которого составляют 132,6 млн т. Месторождение сложено породами кемеровской, ишановской, усятской и алыкаевской свит, в которых сертифицировано 28 угольных пластов. Минимальная мощность пласта простого и сложного строения принята 2 м.

В АО «Сибирский Антрацит» согласно общей классификации экскаваторов, применяемых при добыче полезных ископаемых открытым способом [3, 4], основной экскавационный парк представлен карьерными гидравлическими экскаваторами-лопатами иностранного производства с ковшами вместимостью 7-15 м³ производства Caterpillar (paнеe - Bucyrus) (США), Liebherr (Австрия). Средний возраст парка экскаваторов 8 лет. Основные технические параметры приведены в табл. 1.

\section{Методика обработки исходной информации}

В работе [5], посвященной анализу отказов оборудования и металлоконструкций экскаваторов, выполненной в 1989 г., отмечалось, что действующие в угольной промышленности нормативные документы не способствуют качественному учету условий возникновения отказов. По состоянию на 2020 г. ситуация существенно не изменилась. Основными источниками для получения исходной информации являются отчеты диспетчерских и механических служб, сведения механических служб карьеров о заменах деталей и узлов экскаваторов либо данные эксплуатационных служб сервисных компаний. Существенным недостатком данных источников информации по-прежнему остается возможность предоставления недостоверной информации 
о причинах и условиях отказа при передаче ее по цепочке машинист экскаватора - горный диспетчер - отдел главного механика.

Несмотря на то что на протяжении последних 6-8 лет добычные предприятия РФ осуществляют внедрение автоматизированных систем управления горными работами, качественного изменения с точки зрения повышения достоверности учета отказов не произошло. К основным причинам можно отнести незаинтересованность линейного менеджмента на местах в отражении реальной ситуации на горных работах, отсутствие контроля за корректностью работы системы на вышестоящих уровнях, неиспользование количественных данных, получаемых из таких систем, в операционном и бухгалтерском учетах компаний.

В AO «Сибирский Антрацит» проведением крупноузловых ремонтов КГЭ занимаются эксплуатационные службы сервисных компаний. В данной статье при оценке надежности систем и компонентов систем КГЭ использована информация о простоях экскаваторов из отчетов диспетчерских служб компании, включая данные о датах отказа, времени простоя/ликвидации и дополнительные сведения в случае крупных аварий. Отчеты эксплуатационных служб сервисных компаний оказались полезными в части детализации информации по аварийным отказам. Существенной проблемой являлось отсутствие прозрачной системы учета отказов систем и компонентов систем экскаваторов в части фиксации времени наработки (маш. час, м/ч) между отказами. Частично данную информацию удалось получить из отчетов эксплуатационных служб сервисных компаний. Ввиду этого первоначальный период оценки надежности экскаваторов был сокращен с 8 (2012-2019 гг.) до 3 лет (2017-2019 гг.).

Данные о наработках экскаваторов подвергались предварительной обработке. После систематизации статистических данных было проведено их упорядочение во времени, осуществлена сортировка по типам отказов отдельных систем и их компонентов. Для оценки технических возможностей и показателей работы экскаваторов по статистическим данным определены показатели надежности работы в соответствии с [6, 7]: среднее время между отказами - MTBF, мото. час, среднее время восстановления системы после отказа - MTTR, ч., коэффициент готовности - Кг, вероятность безотказной работы - $\mathrm{P}(\mathrm{t})$.

\section{Структура неплановых простоев парка КГЭ}

Количество простоев экскаваторов - основная характеристика эффективности использования оборудования, что предопределяет востребованность научно обоснованных мероприятий по управлению надежностью экскаваторов, которые позволили бы гарантированно выполнять планируемые производственные программы и снижать расходы на содержание техники [8].

По результатам анализа работы парка КГЭ установлено, что фактическое время работы за период 2017-2019 гг. по экскаваторам Bucyrus RH120E составило 14 021,76 ч, или 29 \% от коэффициента использования календарного фонда времени (КФВ), по экскаваторам Liebherr ER9250 - 38 344,60 ч, или 53 \%, по экскаваторам Liebherr R984C/R9100B - 31 235,46 ч или 61 \% (Liebherr R984C - 60 \%, Liebherr R9100B в 2019 г. - 71 \%). Использование КФВ по типам экскаваторов приведено на рис. 1.

Значительное влияние на время простоев экскаваторов оказали неплановые ремонты из-за отказов и аварий механизмов. Для экскаваторов Bucyrus RH120E доля неплановых простоев в КФВ составила 26 \%, или 2 610,97 ч., Liebherr R984C/R9100B - 31 \%, или 6 266,64 ч. Следует 


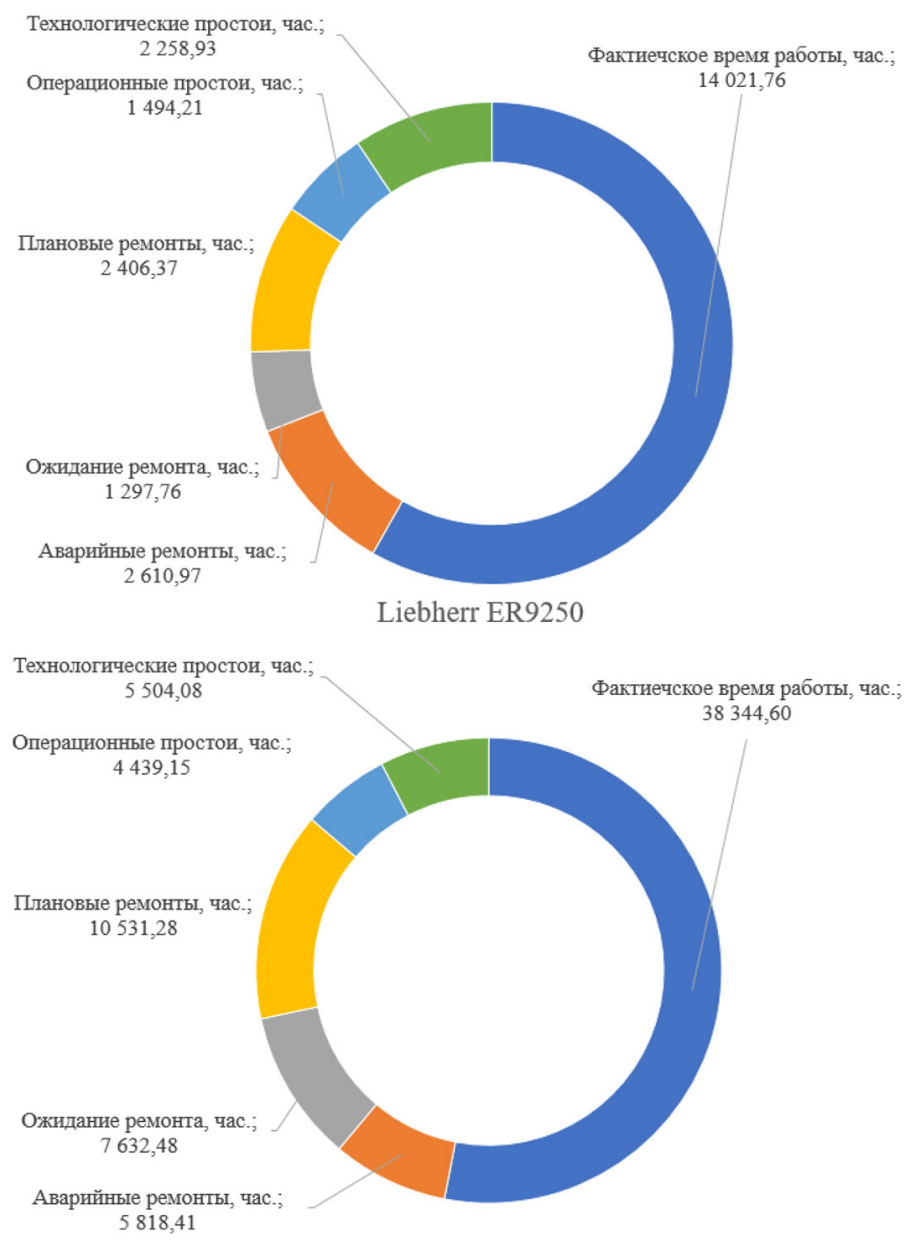

Liebherr 984C/R9100

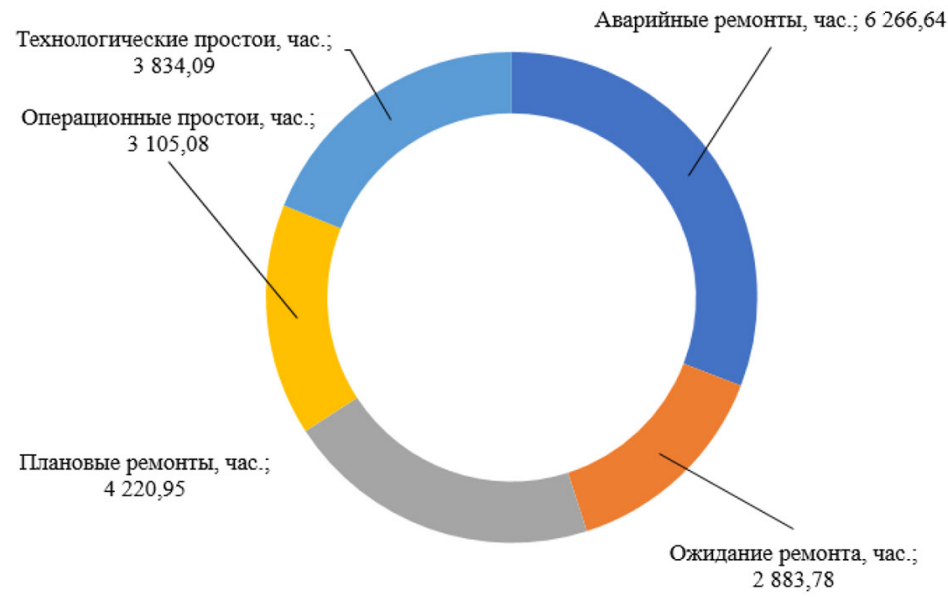

Рис. 1. Использование КФВ экскаваторов Bucyrus RH120E, Liebherr ER9250, R984C/R9100B за период 2012 - 2019 гг.

Fig.1. Use of the Bucyrus RH120E, Liebherr ER9250, R984C/R9100B excavator calendar time fund for the period 2012-2019 
обратить внимание, что в структуре простоев экскаваторов Liebherr ER9250 в анализируемом периоде преобладают простои по причине плановых ремонтов (31 \% или 10 531,28 ч), что обусловлено проведением среднего и капитального ремонта по двум экскаваторам. Несмотря на это, доля неплановых ремонтов из-за отказов и аварий механизмов также высока и составила $17 \%$, или 5818,41 ч.

В статистику неплановых простоев КГЭ АО «Сибирский Антрацит» входят следующие события: отказы и аварии, отказы ЛЭП и отсутствие электроэнергии, отсутствие запасных частей, ожидание ремонтного персонала, отсутствие вспомогательного оборудования/транспорта, климатические и прочие условия, остановки контролирующими органами. В структуре неплановых простоев наибольший удельный вес распределен между следующими событиями: отказы и аварии - $52 \%$, ожидание ремонтного персонала - 35,8 \%, отсутствие запасных частей $-11,1$ \%. Удельный вес отказов по группам «отказы ЛЭП» и «отсутствие электроэнергии», «климатические и прочие условия», «отсутствие вспомогательного оборудования/транспорта», «остановки контролирующими органами - 1,1 \%».

В статистику события «отказы и аварии» включаются простои в связи с отказами основных систем экскаваторов: гидравлическая (ГО), механическая (МО), электрическая (ЭО), двигатель внутреннего сгорания (ДВС), система смазки (СС), а также простои по причинам, оказывающим влияние на восстановление и время нахождения экскаватора в работе: ожидание ремонта $(\mathrm{OP})^{1}$ и внешние причины $(\mathrm{BП})^{2}$.

Результаты анализа структуры неплановых простоев для различных моделей экскаваторов и структура аварийных простоев парка КГЭ приведены на рис. 2 и табл. 2. В общем количестве отказов по КГЭ наибольший вклад вносят простои из-за отказа гидравлической и электрической систем, составляющие 54 \% от их общего количества.

Высокий уровень простоев в ожидании ремонта КГЭ обусловлен непроведением ремонтов в ночную смену, а в дневную смену - ожиданием прибытия сервисных организаций, обслуживающих экскаваторы, простоями по причине отсутствия запасных частей. В условиях угольного разреза «Колыванский» общее время простоев, связанных с отказами вскрышных

Таблица 2. Структура неплановых простоев по системам КГЭ и причинам за 2017-2019 гг.

Table 2. Structure of unplanned downtime by pit hydraulic excavator systems and reasons for 2017-2019

\begin{tabular}{|c|c|c|c|c|c|}
\hline № & Категория отказа & $\begin{array}{c}\text { Bucyrus RH120E, } \\
\%\end{array}$ & $\begin{array}{c}\text { Liebherr ER9250, } \\
\%\end{array}$ & $\begin{array}{c}\text { Liebherr } \\
\text { R984C, } \%\end{array}$ & $\begin{array}{c}\text { Liebherr } \\
\text { R9100B, } \%\end{array}$ \\
\hline 1 & ГО & 19,1 & 18,9 & 29,8 & 32,2 \\
\hline 2 & MО & 12,1 & 13,3 & 6,8 & 5,1 \\
\hline 3 & ЭО & 43,3 & 39,1 & 27,7 & 18,6 \\
\hline 4 & ДВС & - & - & 6 & 18,6 \\
\hline 5 & СС & 8,8 & 4,5 & 9,4 & 18,6 \\
\hline 6 & ОР & 14 & 21,5 & 16,7 & 3,4 \\
\hline 7 & ВП & 2,7 & 2,7 & 3,7 & 3,4 \\
\hline
\end{tabular}

1 Ожидание ремонта в сервисе, отсутствие ремонтной бригады, отсутствие запасных частей.

2 Отключение внешнего электроснабжения, климатические условия, остановка контролирующими органами. 


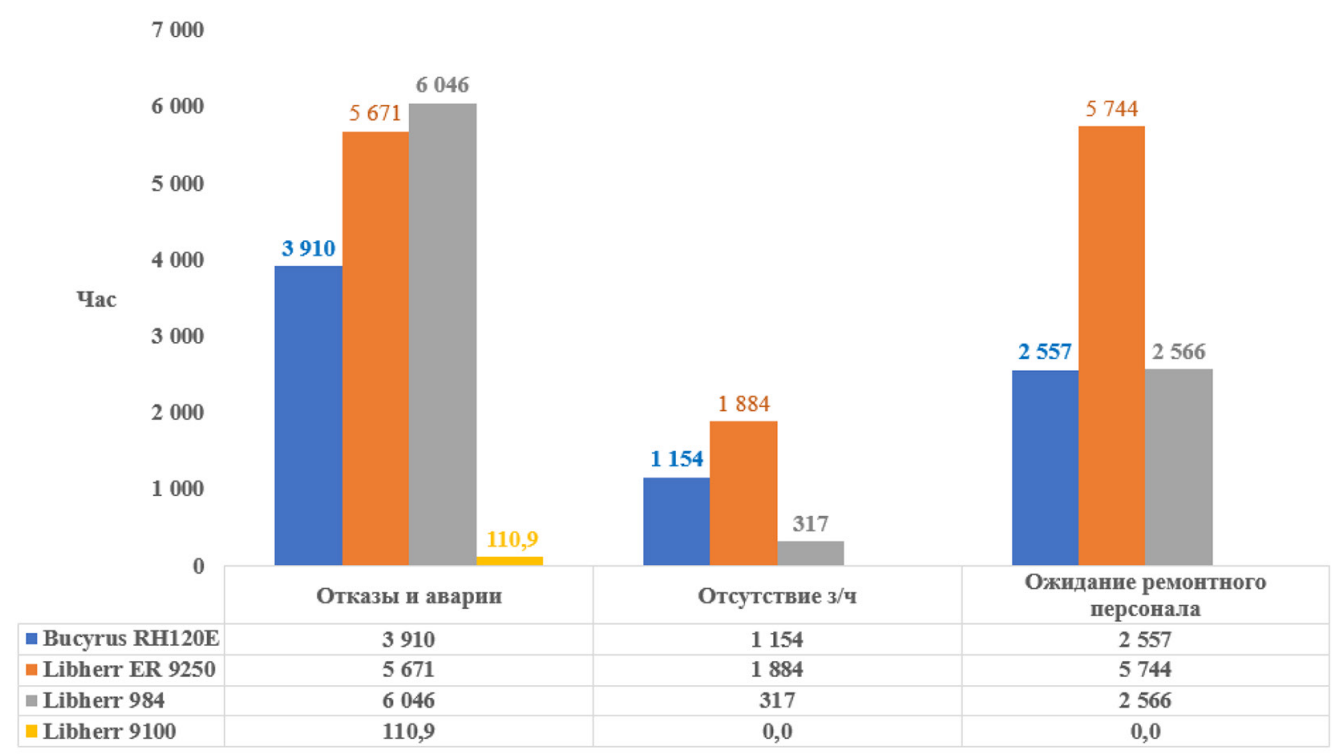

a)

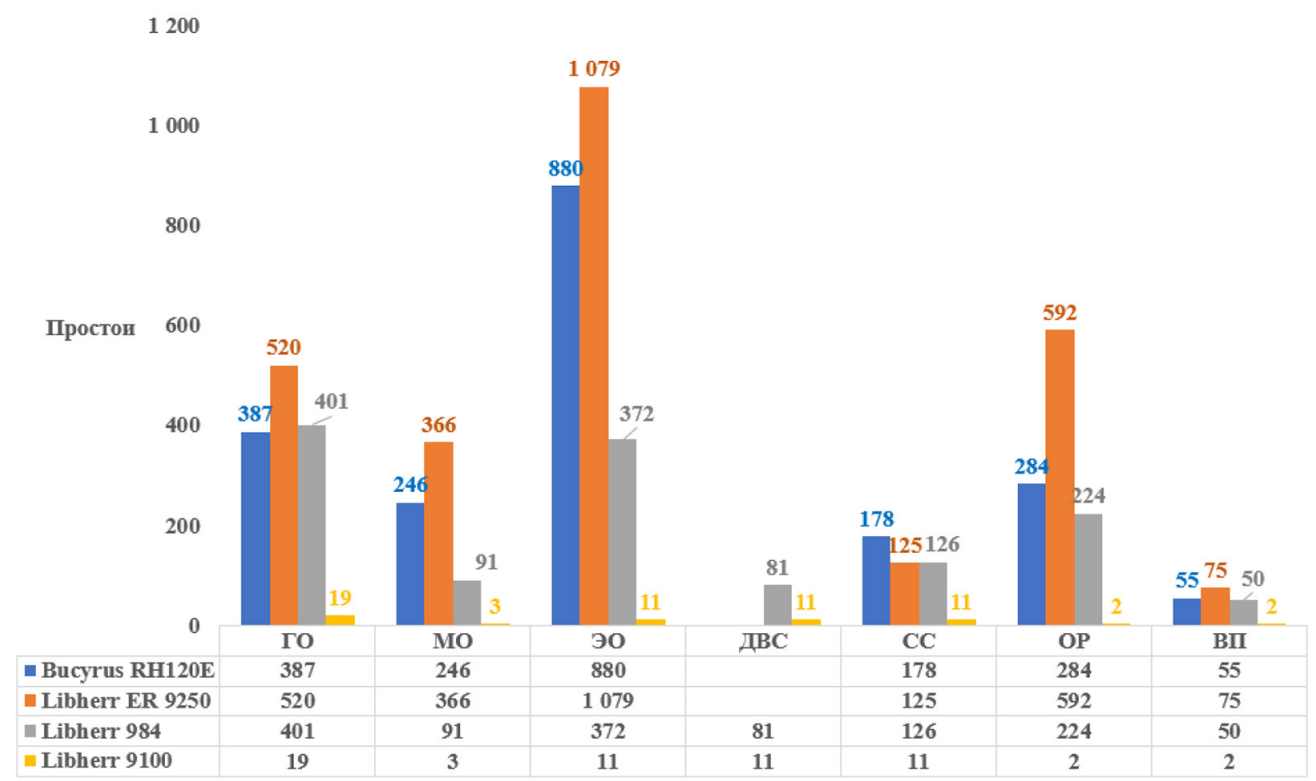

б)

Рис. 2. Структура неплановых простоев вследствие аварийности парка КГЭ за 2017-2019 гг. (а). Структура аварийных простоев парка по системам КГЭ и причинам за 2017-2019 гг. (б)

Fig. 2. Structure of unplanned downtime by pit hydraulic excavator systems and reasons for 2017-2019 (a). Structure of emergency downtime of pit hydraulic excavators and equipment for 2017-2019 (б)

экскаваторов в 2019 г., равнялось 11374 ч. Средняя стоимость одного часа простоя КГЭ на его производительность в 2019 г. рассчитана исходя из прямых затрат (ФОТ персонала, ГСМ/ электроэнергия, амортизация, запасные части) и составила у экскаваторов:

Bucyrus RH120E - 6 768,2 руб/час при производительности 325,8 т/ч;

Liebherr ER9250 - 6 643,9 руб/час при производительности 340,9 т/ч; 
Liebherr R984C - 5 842,6 руб/час при производительности 186,4 т/ч.

\section{Статистическая обработка данных о надежности систем и компонентов КГЭ}

Два экскаватора Bucyrus RH120E с января 2017 г. по январь 2019 г. в сумме наработали 36415 м/ч (табл. 3), при этом было зафиксировано 2030 отказов, в том числе 387 по гидравлическому, 246 по механическому, 880 по электрическому оборудованию, 178 по системе смазки, 284 по ожиданию ремонта и 55 по категории «внешние причины». Средняя наработка двух экскаваторов на отказ составила 17,94 м/ч, а среднее время восстановления - 3,81 ч, что в целом по данной группе экскаваторов обеспечило их готовность к эксплуатации около 82,5%. Безусловная вероятность того, что в интервале наработок от 0 до $10 \mathrm{M} / ч$ (расчетное время рабочей смены) не наступит отказ по группе экскаваторов Bucyrus RH120E №21, №22, paвна P(t) = 0,57 $(57 \%)$.

Из данных табл. 3 следует, что наименьшее суммарное время простоев (595,3 и 1033 м/ч) и наибольшую наработку на отказ (204,6 и 148,03 м/ч) имеют система смазки и механическое оборудование, но при этом они требуют наибольших средних затрат времени на восстановление: 3,34 и 4,2 ч соответственно. Отдельно хотелось бы отметить группу «ожидание ремонта», которая в структуре простоев имеет наибольший удельный вес (48 \%), время восстановления по этой группе составляет 13,03 ч. В 2019 г. по группе «ожидание ремонтов» зафиксировано 117 отказов, общее время восстановления по которым 1546 ч, из которых 1093 ч по причине отсутствия ремонтной бригады, 453,5 ч по причине отсутствия запасных частей. При средней стоимости 1-го часа отказа для данной группы экскаваторов 6768,2 руб. простои по ожиданию ремонтной бригады стоили для компании 7,4 млн руб., простои по отсутствию запасных частей $-3,1$ млн руб.

Три экскаватора Liebherr ER9250 в сумме наработали 48445 м/ч (табл. 4), при этом было зафиксировано 2757 отказов, в том числе 520 по гидравлическому, 366 по механическому, 1079 по электрическому оборудованию, 125 по системе смазки, 592 по ожиданию ремонта и 75 по категории «внешние причины». Средняя наработка трех экскаваторов на отказ равняется

Таблица 3. Основные характеристики показателей надежности экскаватора Bucyrus RH120E

Table 3. Main characteristics of Bucyrus RH120E excavator reliability indicators

\begin{tabular}{|c|c|c|c|c|c|c|c|}
\hline Категория & $\begin{array}{l}\text { Кол-во } \\
\text { отказов }\end{array}$ & $\begin{array}{c}\text { Наработка } \\
\text { всего, м/ч }\end{array}$ & $\begin{array}{c}\text { Время простоев на } \\
\text { восстановление, ч }\end{array}$ & $\begin{array}{l}\mathrm{MTBF}, \\
\mathrm{M} / \mathrm{ч}\end{array}$ & MTTR, ч & \begin{tabular}{|c|} 
Кг \\
$2017-2019$ гг., \\
$\%$
\end{tabular} & $\mathrm{P}(\mathrm{t})$ \\
\hline$\Gamma \mathrm{O}$ & 387 & \multirow{6}{*}{36415} & 1289,51 & 94,1 & 3,33 & 96,58 & 0,90 \\
\hline $\mathrm{MO}$ & 246 & & 1033,15 & 148,03 & 4,2 & 97,2 & 0,93 \\
\hline ЭО & 880 & & 1003,33 & 41,38 & 1,14 & 97,3 & 0,79 \\
\hline $\mathrm{CC}$ & 178 & & 595,28 & 204,58 & 3,34 & 98,4 & 0,95 \\
\hline OP & 284 & & 3700,08 & 128,22 & 13,03 & 90,8 & 0,92 \\
\hline ВП & 55 & & 103,82 & 662,09 & 1,89 & 99,7 & 0,99 \\
\hline Итого & 2030 & 36415 & 7725,17 & 17,94 & 3,81 & 82,5 & 0,57 \\
\hline
\end{tabular}


Таблица 4. Основные характеристики показателей надежности экскаватора Liebherr ER9250

Table 4. Main characteristics of Liebherr ER9250 excavator reliability indicators

\begin{tabular}{|c|c|c|c|c|c|c|c|}
\hline Категория & $\begin{array}{l}\text { Кол-во } \\
\text { отказов }\end{array}$ & $\begin{array}{c}\text { Наработка } \\
\text { всего, м/ч }\end{array}$ & $\begin{array}{c}\text { Время простоев на } \\
\text { восстановление, ч }\end{array}$ & $\begin{array}{l}\mathrm{MTBF}, \\
\mathbf{M} / \mathbf{ч}\end{array}$ & MTTR, ч & $\begin{array}{c}\text { Кг } \\
2017-2019 \text { гг., } \\
\%\end{array}$ & $\mathrm{P}(\mathrm{t})$ \\
\hline$\Gamma \mathrm{O}$ & 520 & \multirow{6}{*}{48445} & 1677,02 & 93,16 & 3,23 & 96,7 & 0,9 \\
\hline $\mathrm{MO}$ & 366 & & 2376,38 & 132,36 & 6,49 & 95,3 & 0,93 \\
\hline ЭО & 1079 & & 1346,71 & 44,9 & 1,25 & 97,3 & 0,8 \\
\hline $\mathrm{CC}$ & 125 & & 286,43 & 387,56 & 2,29 & 99,4 & 0,97 \\
\hline OP & 592 & & 7613,68 & 81,83 & 12,86 & 86,4 & 0,88 \\
\hline ВП & 75 & & 131,87 & 645,93 & 1,76 & 99,7 & 0,98 \\
\hline Итого & 2757 & 48445 & 13432,09 & 17,57 & 4,87 & 78,3 & 0,56 \\
\hline
\end{tabular}

17,57 м/ч, а среднее время восстановления - 4,87 ч, что в целом по данной группе экскаваторов обеспечило их готовность к эксплуатации около 78,3%. Безусловная вероятность того, что в интервале от 0 до 10 м/ч (расчетное время рабочей смены) не наступит отказ по группе экскаваторов Liebherr ER9250 №19, №20, №23, составляет P(t) = 0,56 (56 \%). Наименьшее суммарное время простоев (286,4 и 1347 ч) приходится на группы «система смазки» и «электрическое оборудование». Наибольшую наработку на отказ (387,6 и 132,4 м/ч) имеют система смазки и механическое оборудование, как следствие, у данных систем самый высокий коэффициент готовности. При этом наибольших средних затрат времени на восстановление требует механическое оборудование - 6,5 ч - и гидравлическая система - 3,23 ч, несмотря на то, что у гидравлической системы довольно высокая наработка на отказ. Группа «ожидание ремонта» в структуре простоев имеет удельный вес (21%), и время восстановления по этой группе равно 12,86 ч. В 2019 г. по группе «ожидание ремонтов» зафиксировано 240 отказов, общее время восстановления по которым составило 2943 ч, из которых 2676 ч по причине отсутствия ремонтной бригады, 267,1 ч по причине отсутствия запасных частей. При средней стоимости 1-го часа отказа для данной группы экскаваторов 6 643,9 руб. простои по ожиданию ремонтной бригады стоили для компании 17,8 млн руб., простои по отсутствию запасных частей - 1,8 млн руб.

Два экскаватора Liebherr R984C с января 2017 г. по январь 2019 г. в сумме наработали 40210 м/ч (табл. 5), при этом было зафиксировано 1689 отказов, в том числе 503 по гидравлическому, 449 по механическому, 117 по электрическому оборудованию, 169 по системе смазки, 146 по системе двигателя внутреннего сгорания, 248 по ожиданию ремонта и 157 по категории «внешние причины». Средняя наработка двух экскаваторов на отказ составила 23,81 м/ч, а среднее время восстановления - 5,35 ч., что в целом по данной группе экскаваторов обеспечило их готовность к эксплуатации около 81,7 \%. Безусловная вероятность того, что в интервале от 0 до 10 м/ч (расчетное время рабочей смены) не наступит отказ по группе экскаваторов Liebherr $\mathrm{R} 984 \mathrm{C}$ №26, №28, составляет P(t) = 0,66 (66 \%). Из данных табл. 5 следует, что наименьшее суммарное время простоев (352 ч) и наибольшую наработку на отказ (343,7 м/ч) имеет электрическое оборудование. При этом наибольших средних затрат времени на восстановление требует группа ДВС (9,6 ч). У экскаваторов Liebherr R984C самое высокое значение времени восстанов- 
Таблица 5. Основные характеристики показателей надежности экскаватора Liebherr R984C

Table 5. Main characteristics of Liebherr R984C excavator reliability indicators

\begin{tabular}{|c|c|c|c|c|c|c|c|}
\hline Категория & $\begin{array}{l}\text { Кол-во } \\
\text { отказов }\end{array}$ & $\begin{array}{l}\text { Наработка } \\
\text { всего, м/ч }\end{array}$ & $\begin{array}{l}\text { Время простоев на } \\
\text { восстановление, ч }\end{array}$ & MTBF, м/ч & MTTR, ч & \begin{tabular}{|c|} 
Кг \\
$2017-2019$ гг., \\
$\%$
\end{tabular} & $\mathrm{P}(\mathrm{t})$ \\
\hline$\Gamma \mathrm{O}$ & 146 & \multirow[t]{7}{*}{40210} & 1407 & 275,41 & 9,64 & 96,6 & 0,96 \\
\hline ДВС & 449 & & 2027 & 89,55 & 4,52 & 95,2 & 0,89 \\
\hline $\mathrm{MO}$ & 117 & & 352 & 343,68 & 3,01 & 99,1 & 0,97 \\
\hline ЭО & 169 & & 449 & 237,93 & 2,66 & 98,9 & 0,96 \\
\hline $\mathrm{CC}$ & 248 & & 2883 & 162,14 & 11,63 & 93,3 & 0,94 \\
\hline $\mathrm{OP}$ & 157 & & 95 & 705,44 & 1,66 & 99,8 & 0,99 \\
\hline ВП & 146 & & 1407 & 275,41 & 9,64 & 96,6 & 0,96 \\
\hline Итого & 1689 & 40210 & 9036,47 & 23,81 & 5,35 & 81,7 & 0,66 \\
\hline
\end{tabular}

ления составило 11,63 ч по группе «ожидание ремонта». В 2019 г. по группе «ожидание ремонта» зафиксировано 118 отказов, общее время восстановления по которым равнялось 1406 ч, из которых 1 269,27 ч по причине отсутствия ремонтной бригады, 136,50 ч по причине отсутствия запасных частей. При средней стоимости 1-го часа отказа для данной группы экскаваторов 5 311,46 руб. простои по ожиданию ремонтной бригады стоили для компании 6,7 млн руб., простои по отсутствию запасных частей - 725 тыс. руб.

\section{Заключение}

1. По результатам анализа показателей надежности систем и компонентов КГЭ установлено, что среди экскаваторов с ковшом $15 \mathrm{~m}^{3}$ более высокий индекс надежности имеет экскаватор марки Bucyrus RH120E. По сравнению с экскаваторами марки Liebherr ER 9250 у экскаваторов Bucyrus RH120 меньшее время простоев на восстановление - 7 725,17 часа к 13432 часа, более высокий индекс наработки на отказ - 17,94 к 17,57 м/ч и меньший индекс среднего времени на восстановление - 3,81 к 4,87 ч. Как следствие, коэффициент готовности Bucyrus RH120E coставил 82,5 \%, a Liebherr ER 9250 - 78,3 \%, а безусловная вероятность того, что в интервале от 0 до 10 м/ч не наступит отказ по экскаватору Bucyrus RH120, равна $\mathrm{P}(\mathrm{t})=0,573$ (57 \%) при 0,566 (56\%) у Liebherr ER 9250.

Индекс надежности экскаваторов с ковшом $7 \mathrm{~m}^{3}$ марки Liebherr R984C составляет $\mathrm{P}(\mathrm{t})=0,66(66 \%)$ при коэффициенте готовности $81,7 \%$. Время простоев на восстановление равно 9 036,47 ч, что ниже, чем у Bucyrus RH120Е. При этом наработка на отказ составляет 23,81 м/ч, что выше, чем у экскаваторов с объемом ковша 15 м³. Рейтинг надежности среди гидравлических экскаваторов, эксплуатируемых в условиях угольного разреза «Колыванский», отображен в табл. 6.

2. Высокий уровень неплановых простоев экскаваторов приводит к ощутимым затратам, что обусловлено не только снижением объема экскавации угля и породы, но и ростом издержек на проведение ремонтов. В 2019 г. по группе «ожидание ремонтов» всего зафиксировано 475 отказов. Разрез «Колыванский» понес издержки по причине простоев в ожидании ремонтной 
Таблица 6. Рейтинг надежности основных групп оборудования КГЭ

Table 6. Reliability rating of the main groups of equipment for pit hydraulic excavators

\begin{tabular}{|l|c|c|c|c|}
\hline \multirow{2}{*}{ Экскаватор } & \multicolumn{3}{|c|}{ Вероятность безотказной работы за 10 м/ч для групп оборудования } \\
\cline { 2 - 5 } & ГО & MO & ЭО & CC \\
\hline Bucyrus RH120E $\left(15 \mathrm{~m}^{3}\right)$ & 0,899 & 0,935 & 0,785 & 0,952 \\
\hline Liebherr ER9250 $\left(15 \mathrm{~m}^{3}\right)$ & 0,898 & 0,927 & 0,800 & 0,975 \\
\hline Liebherr R984C $\left(7 \mathrm{~m}^{3}\right)$ & 0,885 & 0,898 & 0,970 & 0,959 \\
\hline
\end{tabular}

бригады в размере 31,9 млн руб., издержки по причине простоев по отсутствию запасных частей 5,6 млн руб.

Снижение издержек по данной группе можно достигнуть за счет организации проведения ремонтно-восстановительных работ в ночную смену (сокращение сменного простоя), размещения специалистов сервисных организаций в границах ведения горных работ (сокращение времени прибытия сервисных специалистов на разрез), внедрения политики планирования и проведения ремонтов, обеспечивающей своевременную замену расходных и изнашивающихся элементов, для достижения заданных сроков эксплуатации экскаваторов и определения срока службы до списания.

3. Таким образом, по результатам анализа показателей эксплуатационной надежности карьерных гидравлических экскаваторов выявлены «узкие места» в процессе управления парком экскаваторов в условиях угольного разреза «Колыванский», заключающиеся:

- $\quad$ в необходимости сокращения простоев по группе «ожидание ремонтов». Экономический эффект от реализации данного мероприятия будет выражаться в сокращении прямых затрат на содержание экскаваторов, а также в повышении их производительности;

- в выявлении наиболее проблемных групп оборудования для моделей экскаваторов, требующих пересмотра текущей стратегии управления ремонтами в целях повышения их отказоустойчивости.

\section{Список литературы / References}

[1] Таразанов И.Г., Губанов Д.А. Итоги работы угольной промышленности России за январь -декабрь 2020 года. Уголь, 2020, 3, 54-69. DOI: 10.18796/0041-5790-2020-3-54-69. [Tarazanov I., Gubanov D. Results of the Russian coal industry in January-December 2020, Coal, 2020, 3, 54-69 (in Russian)].

[2] Федеральная служба государственной статистики. Российский статистический ежегодник. 2019 г. URL: https://www.gks.ru/. [Federal state statistics service. Russian statistical Yearbook, 2019. URL: https://www.gks.ru/ (in Russian)].

[3] Домбровский Н.Г. Экскаваторы. Общие вопросы теории, проектирования и применения. М.: Машиностроение, 1962. 318 с. [Dombrowski N.G. The excavators. General questions of theory, design and application. Moscow, Mashinostroenie, 1962. 318 p. (in Russian)].

[4] Подэрни Р.Ю. Горные машины и комплексы для открытых работ. М.: Недра, 1985. 544 c. [Poderni R. Mining machines and complexes for open works. Moscow, Nedra, 1985. 544 p. (in Russian)].

$$
-755-
$$


[5] Анализ отказов механического оборудования и металлоконструкций экскаваторов. Москвичев В.В., Доронин С.В., Утехин С.А. Эбич В.Р. Красноярск: ВЦ СО АН СССР, 1989. 33 с. [Analysis of failures of mechanical equipment and metal structures of excavators. Moskvichev V., Doronin S., Utekhin S., Ebich V. Krasnoyarsk: VTS SO AN USSR, 1989. 33 p. (in Russian)].

[6] ГОСТ 27.002-2015 Надежность в технике (ССНТ). Термины и определения. Введ. № 2017-03-01. М.: Стандартинформ, 2016. 22 с. [GOST 27.002-2015 Reliability in engineering (SSNT). Terms and definitions. No. 2017-03-01. Moscow: standardinform, 2016. 22 p. (in Russian)].

[7] Торелл В., Авелер В. Среднее время между отказами: описание, стандарты. Информационная статья № 72, APC, Legendary Reliability. [Torell V., Aveler V., Average time between failures: description, standards. Information article \# 72, APC, Legendary Reliability (in Russian)].

[8] Богомолов И.Д., Буянкин П.В. Состояние рабочего оборудования экскаваторного парка Кузбасса. Сборник лучших докладов студентов и аспирантов Кузбасского государственного технического университета по результатам юбилейной 50-й научно-практической конференции, ГУ КузГТУ, 18-23 апр. 2005. Кемерово, 2005, 79-81. [Bogomolov I.D., Buyankin P.V. State of the working equipment of the Kuzbass excavator Park. Collection of the best reports of students and postgraduates of the Kuzbass state technical University on the results of the 50th anniversary scientific and practical conference, GU KuzSTU, 18-23 APR. 2005. Kemerovo, 2005, 79-81 (in Russian)]. 